\title{
New insights about the formation of copper ferrite: in situ X-ray diffraction study
}

\author{
Eman Z Hegazy ${ }^{1,2^{*}}$ (D) Islam H Abd El-Maksod ${ }^{1,2}$, Amal M Ibrahim ${ }^{2,3}$ and Shaymaa El-Sayed El-Shafay ${ }^{2}$
}

\begin{abstract}
Background: As the copper ferrite gains more attention due to its unique electronic, thermal, and catalytic properties, the need to explore the mechanism of its formation is becoming a task to be studied.

Results: The mechanism of copper ferrite formation was studied by in situ XRD, and IR results showed comparison that the formation of $\mathrm{Fe}_{3} \mathrm{O}_{4}$ was formed by in situ heating.

Conclusions: These results shed light on the formation of ferrite first begun with the formation of $\mathrm{Fe}_{3} \mathrm{O}_{4}$, and then, incorporation of $\mathrm{Cu}^{2+}$ ion is done.
\end{abstract}

Keywords: Cupper ferrites, XRD, Incorporation

\section{Background}

Spinel ferrites are showing increasing interest in the past few decades due to their unique electronic, magnetic, and catalytic properties. These properties make ferrites have their exclusive field of applications, among these applications are recording device, medical application, electronic devices, and catalytic application including an important contribution in $\mathrm{CO}_{2}$ decomposition (Gunther 1990; Ding et al. 1998; Mazaleyrat and Varga 2000; Riley et al. 2002; Tamaura and Tahata 1990). Among the most important ferrite spinel systems, the copper/iron/oxygen system is attracting more interest in many fields such as solid-state physics, ceramics, metallurgy, and mineralogy. Copper ferrites gather more interest because of its unique properties regarding its electrical conductivity in combination with semiconducting behavior. In addition to its thermal stability, copper ferrite showed a considerable catalytic activity for oxygen generation (McCurrie 1994; Stewart et al. 2004). The framework of copper ferrite is considered to be inverse spinel. Copper and iron ions could be positioned in different crystallographic positions surrounded by oxygen atoms in a cubic closed pack structure. Nominated as A and B sites, the ions could occupy either tetrahedral or octahedral positions. The formula of this type of allocations is represented as

\footnotetext{
* Correspondence: ehegazy77@yahoo.com

${ }^{1}$ King Abdulaziz University, Jeddah, Saudi Arabia

${ }^{2}$ National Research Centre (NRC), El Buhuoth St., Dokki, Cairo 12622, Egypt

Full list of author information is available at the end of the article
}

$\left(\mathrm{Cu}_{x} \mathrm{Fe}_{1 \_x}\right) \mathrm{A}\left(\mathrm{Cu}_{1 \_x} \mathrm{Fe}_{1+x}\right) \mathrm{BO}_{4}$, where $x$ is the inversion coefficient assigned to be zero or one describing the inverse or normal spinel (Agouriane et al. 2016). Copper ferrite can exist in two different spinel arrangements (Atia et al. 2016): cubic one exists at high temperature accompanied with lattice constant of $8.38 \mathrm{~A}^{\circ}$ and the tetragonal one assigned with lattice constants of $a=8.216$ $\mathrm{A}^{\circ}, c=8.709 \mathrm{~A}^{\circ}$. The inverse model pattern composed of eight copper ions octahedrally positioned (B) and 16 iron ions in trivalent state distributed equally along the tetrahedral and octahedral positions (Jiang et al. 1999; Muthukumar et al. 2018; Schaefer et al. 1970; Goya et al. 1998). It is established that the production way plays an awfully significant function in the chemical and magnetic property of resulted ferrites, and one of the most important challenges is to explore the structure formation mechanism in order to manipulate and control formation condition to target certain structure to be applied in a specific and selective field of applications. In this paper, we would like to shed some light on how the $\mathrm{Cu}^{2+}$ enters in the spinel structure by using in situ XRD measurements.

\section{Methods \\ Materials}

The materials used are $\mathrm{Cu}\left(\mathrm{NO}_{3}\right) \cdot 3 \mathrm{H}_{2} \mathrm{O} 99.5 \%$ (Merck), $\mathrm{Fe}\left(\mathrm{NO}_{3}\right)_{3} .9 \mathrm{H}_{2} \mathrm{O} 99 \%$ (Merck), and $\mathrm{NaOH} 97 \%$ (Merck). 


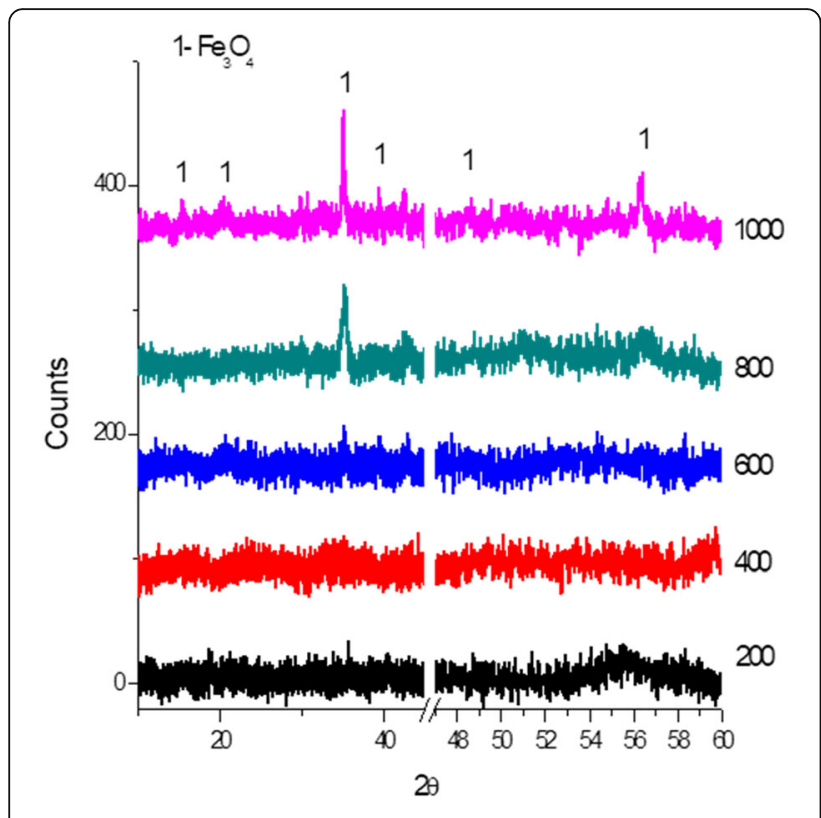

Fig. 1 In situ calcination XRD spectra of $\mathrm{Cu}-\mathrm{Fe}$ precursors

\section{Method of preparation}

A solution of copper/iron with 2:1 $\mathrm{M}$ ratio was prepared in a $200-\mathrm{ml} \mathrm{H}_{2} \mathrm{O}$. An equivalent amount of $\mathrm{NaOH}$ solution was added dropwisely till complete precipitation, and then, the precipitate was washed and dried at $100^{\circ}$ $\mathrm{C}$ overnight. Calcination was performed at $200{ }^{\circ} \mathrm{C}$. In situ calcination at different temperatures was done in the temperature chamber of XRD instrument.

\section{Results}

XRD spectra

XRD diffractograms of in situ measurements of $\mathrm{Cu}-\mathrm{Fe}$ precursors were showed in (Fig. 1).

The XRD diffractograms showed that even at $600{ }^{\circ} \mathrm{C}$, amorphous phase was observed. Moreover, as the calcination temperature increased up to $800{ }^{\circ} \mathrm{C}$, a $\mathrm{Fe}_{3} \mathrm{O}_{4}$, phase started to appear being very clear at $1000{ }^{\circ} \mathrm{C}$ (Fig. 2).

Fourier transform infrared spectrophotometer (FTIR)

Figure 3 shows IR spectra of dried $\mathrm{Cu}$ :Fe sample, calcined at $200{ }^{\circ} \mathrm{C}$ and at $1000{ }^{\circ} \mathrm{C}$.

\section{Discussion}

The mechanism of the formation of $\mathrm{CuFeO}_{4}$ could be assumed to consist of two steps depending on the fact that the aqueous $\mathrm{NaOH}$ solution acts as a reducing agent using the property of $\mathrm{OH}^{-}$group which could lose electron according to Scheme 1.

\section{Techniques}

X-ray diffraction spectroscopy (XRD) was measured using Bruker D8 Advance at $40 \mathrm{~mA}$ and $40 \mathrm{Kv}$, operated with temperature unit. Fourier transform infrared spectroscopy was collected using Bruker IR spectrophotometer.

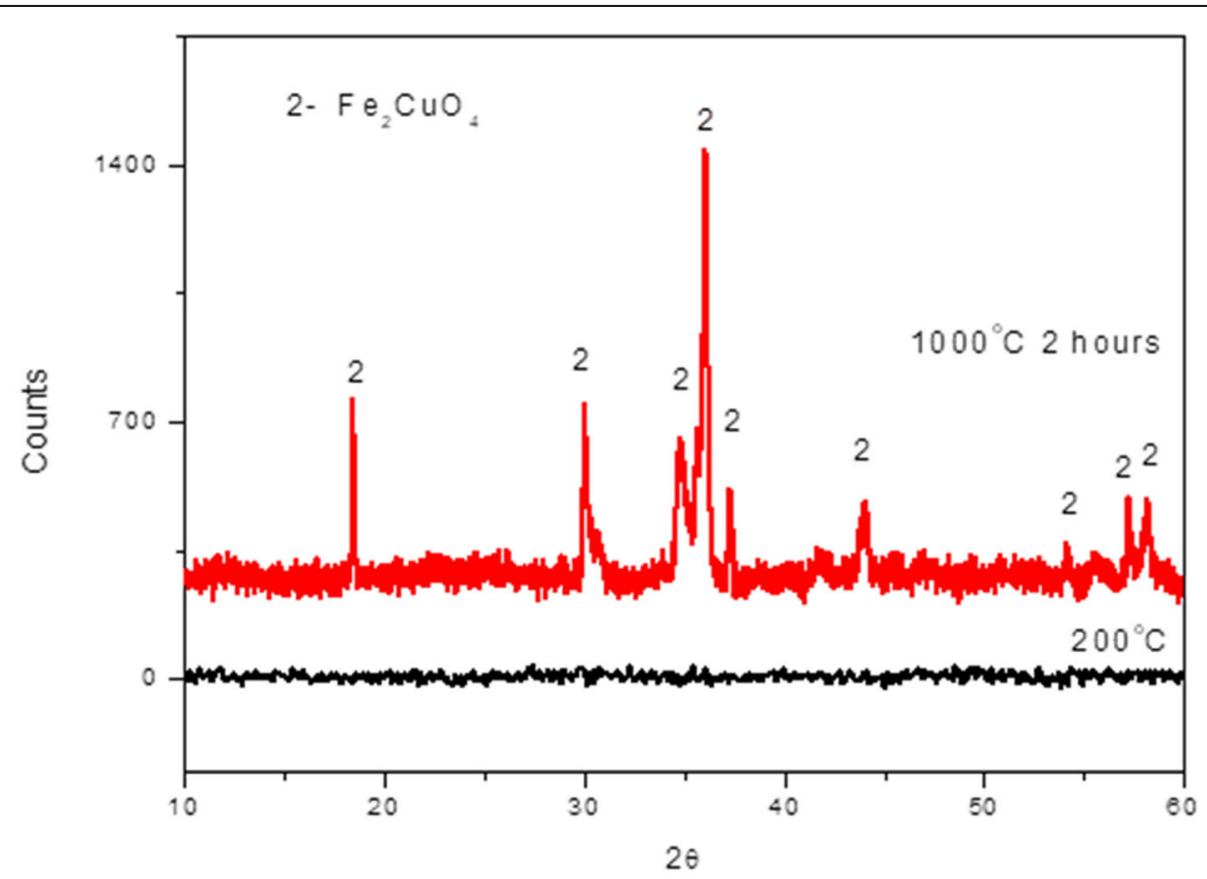

Fig. 2 XRD spectra of Cu:Fe precursors calcined at $200{ }^{\circ} \mathrm{C}$ and at $1000{ }^{\circ} \mathrm{C}$ 


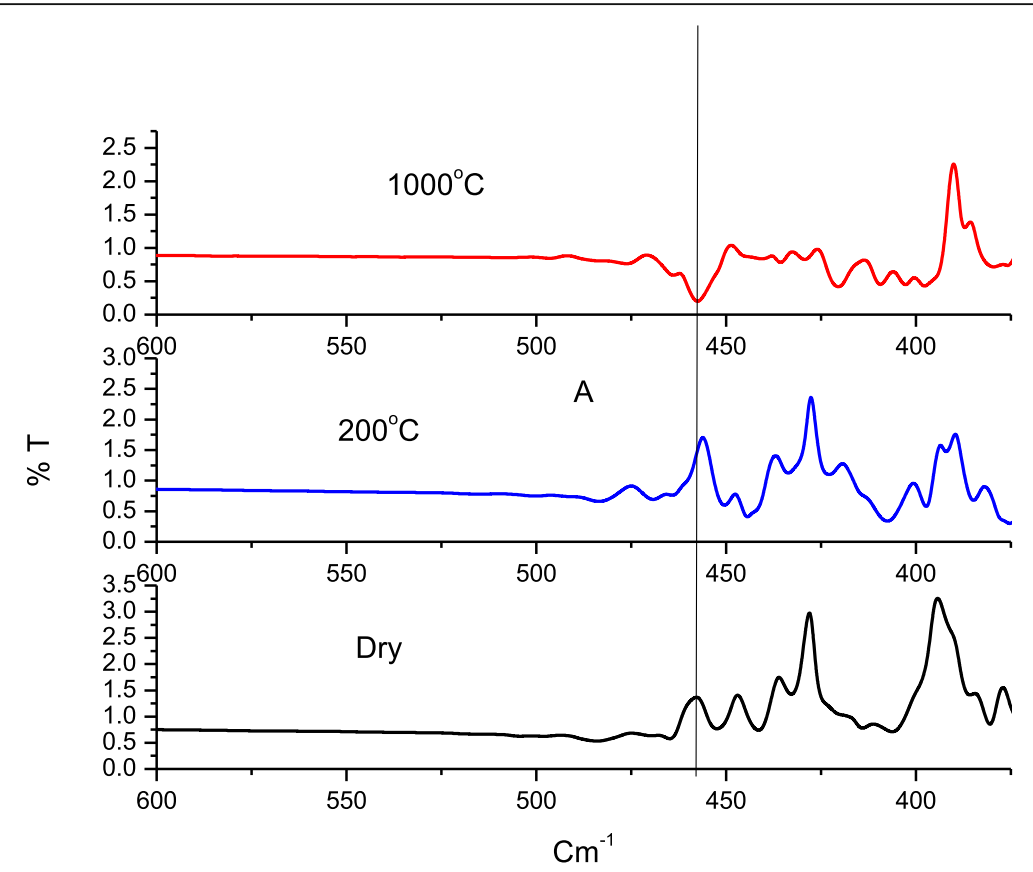

Fig. 3 IR spectra of dried Cu:Fe sample, calcined at $200{ }^{\circ} \mathrm{C}$ and at $1000{ }^{\circ} \mathrm{C}$

Four concurrent processes occur first, and second processes (Scheme 2) involve the reaction of $\mathrm{Cu}^{2+}$ and $\mathrm{Fe}^{3+}$ producing the formation of iron(III) oxide and copper(II) oxide from their hydroxides as it is well known.

The heat involved in the conversion of iron(III) hydroxide into iron(III) oxide could be obtained from the solvation process of $\mathrm{NaOH}$. Third concurrent process occurs due to the reducing property of the hydroxyl group which reduces $\mathrm{Fe}^{3+}$ to form $\mathrm{Fe}^{2+}$. $\mathrm{Fe}^{2+}$ reacts with $\mathrm{OH}^{-}$to form iron(II) hydroxide which in the second step produces iron(II) oxide (Scheme 3).

The final process is the reaction of the coexistence of different hydroxides (Scheme 4).

The above scheme could be complimentary to previous data studied by Kolta et al. (1981). Thus, they revealed a mechanism based on two steps and they suggest the last step at high temperature is the formation of ferrites. In our study, we declare that it could be explained by the formation of $\mathrm{Fe}_{3} \mathrm{O}_{4}$ in the first step followed by the insertion of copper ions in the last steps as could be seen from previous equations.

\section{XRD spectra}

XRD diffractograms of in situ measurements of $\mathrm{Cu}-\mathrm{Fe}$ precursors were showed in (Fig. 1). The XRD diffractograms showed that even at $600{ }^{\circ} \mathrm{C}$, amorphous phase was observed. Moreover, as the calcination temperature increased up to $800{ }^{\circ} \mathrm{C}$, a $\mathrm{Fe}_{3} \mathrm{O}_{4}$ phase started to appear being very clear at $1000{ }^{\circ} \mathrm{C}$. To confirm these results, we perform calcination of $\mathrm{Cu}: \mathrm{Fe}$ precursors in a muffle furnace for $2 \mathrm{~h}$. Although the same temperature of calcination, the prolonged heating in a muffle furnace showed only copper ferrite phase (Fig. 2). These results revealed that the $\mathrm{Fe}_{3} \mathrm{O}_{4}$ is being crystalized first, and then, incorporation of copper to form copper ferrite is being crystalized in a later stage. This shed some light on the mechanism of formation of copper ferrite which seemed to be formed only at high temperatures.

FTIR

Figure 3 shows IR spectra of dried $\mathrm{Cu}: \mathrm{Fe}$ sample, calcined at $200{ }^{\circ} \mathrm{C}$ and at $1000{ }^{\circ} \mathrm{C}$.

The FTIR spectra of $\mathrm{Cu}$ :Fe sample calcined at different temperatures are showed in Fig. 3. The spectra showed that the fingerprint region $375-400$ is nearly the same for dried and $200{ }^{\circ} \mathrm{C}$ samples which reflect the vibration of separate $\mathrm{Fe}-\mathrm{O}$ and $\mathrm{Cu}-\mathrm{O}$ vibration modes. However, the sample calcined at $1000{ }^{\circ} \mathrm{C}$ showed some differentiated peaks especially at $457^{\circ} \mathrm{C}$ which may be devoted to $\mathrm{Cu}-\mathrm{Fe}-\mathrm{O}$ vibration mode in spinel structure of copper ferrite.

\section{Conclusions}

The study of the formation of copper-iron binary oxide system by using in situ XRD measurements helped in

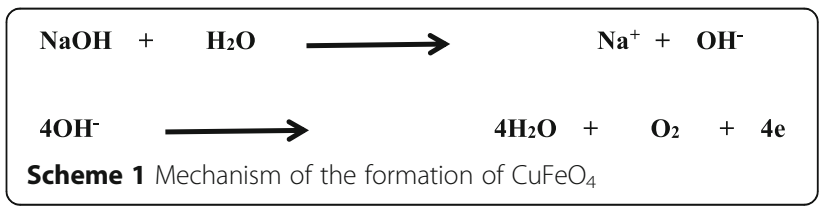




\begin{tabular}{|l}
$2 \mathrm{Fe}(\mathrm{OH})_{3}$ \\
$\mathrm{Fe}^{3+}+\mathrm{SuH}^{-2}$
\end{tabular}

Scheme $3 \mathrm{Fe}^{2+}$ reacts with $\mathrm{OH}^{-}$to form iron(II) hydroxide which in the second step produces iron(II) oxide

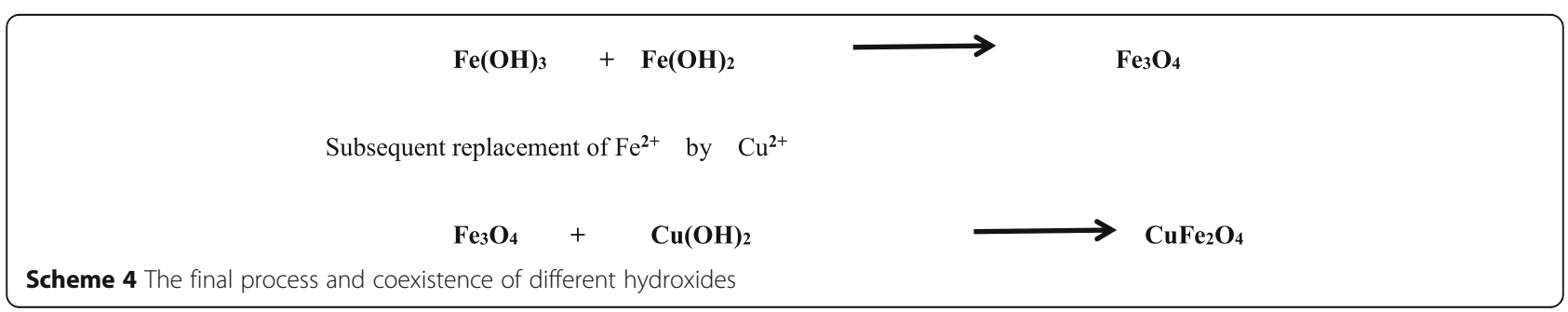


exploring the mechanism of ferrite formation and the sequence of the binary system oxide formation. It was proved that the $\mathrm{Fe}_{3} \mathrm{O}_{4}$ is being formed firstly followed by the incorporation of $\mathrm{Cu}$ in the lattice reforming the structure into a spinel structure.

The application of copper ferrite formed could be used in many industrial applications depending on its magnetic and thermal properties.

\section{Acknowledgements}

All authors acknowledge the National Research Center Labs for making the analysis on it.

\section{Availability of data and materials}

All data generated or analyzed during this study are included in this published article [and its supplementary information files].

\section{Authors' contributions}

All authors contribute in the work and writing the manuscript. All authors read and approved the final manuscript.

\section{Ethics approval and consent to participate}

Manuscript does not contain studies involving human participants, human data, or human tissue.

\section{Consent for publication}

Not applicable

\section{Competing interests}

The authors declare that they have no competing interests.

\section{Publisher's Note}

Springer Nature remains neutral with regard to jurisdictional claims in published maps and institutional affiliations.

\section{Author details}

${ }^{1}$ King Abdulaziz University, Jeddah, Saudi Arabia. ${ }^{2}$ National Research Centre (NRC), El Buhuoth St., Dokki, Cairo 12622, Egypt. ${ }^{3} J$ Jeddah University, Jeddah, Saudi Arabia.

Received: 28 June 2018 Accepted: 20 September 2018

Published online: 10 October 2018

\section{References}

Agouriane E, Rabi B, Essoumhi A, Razouk A, Sahlaoui M, Costa B, Sajieddine M (2016) Structural and magnetic properties of $\mathrm{CuFe}_{2} \mathrm{O}_{4}$ ferrite nanoparticles synthesized by co-precipitation. J Mater Environ Sci 7(11):4116-4120

Atia TA, Altimari P, Moscardini E, Pettiti I, Toro L, Pagnanelli F (2016) Synthesis and characterization of copper ferrite magnetic nanoparticles by hydrothermal route. Chem Eng Trans 47

Ding J, Miao W, McCormick P, Street R (1998) High-coercivity ferrite magnets prepared by mechanical alloying. J Alloys Compd 281(1):32-36

Goya G, Rechenberg H, Jiang J (1998) Structural and magnetic properties of ball milled copper ferrite. J Appl Phys 84(2):1101-1108

Gunther $L$ (1990) Quantum tunnelling of magnetisation. Physics World 3(12):28

Jiang J, Goya G, Rechenberg H (1999) Magnetic properties of nanostructured $\mathrm{CuFe}_{2} \mathrm{O}_{4}$. J Phys Condens Matter 11(20):4063

Kolta GA, El-Tawil SZ, Ibrahim AA, Felix NS (1981) Kinetics and mechanism of copper ferrite formation. Thermochim Acta 43(3):279-287

Mazaleyrat F, Varga L (2000) Ferromagnetic nanocomposites. J Magn Magn Mater 215:253-259

McCurrie RA (1994) Ferromagnetic materials: structure and properties. London : Academic Press, cop

Muthukumar K, Lakshmi DS, Acharya SD, Natarajan S, Mukherjee A, Bajaj H (2018) Solvothermal synthesis of magnetic copper ferrite nano sheet and its antimicrobial studies. Mater Chem Phys 209:172-179

Riley M, Walmsley A, Speight J, Harris I (2002) Magnets in medicine. Mater Sci Technol 18(1):1-12
Schaefer S, Hundley G, Block F, McCune R, Mrazek R (1970) Phase equilibria and $X$-ray diffraction investigation of the system $\mathrm{Cu}-\mathrm{Fe}-\mathrm{O}$. Metall Trans 1(9):2557 Stewart S, Tueros M, Cernicchiaro G, Scorzelli R (2004) Magnetic size growth in nanocrystalline copper ferrite. Solid State Commun 129(6):347-351

Tamaura Y, Tahata M (1990) Complete reduction of carbon dioxide to carbon using cation-excess magnetite. Nature 346(6281):255

\section{Submit your manuscript to a SpringerOpen ${ }^{\circ}$ journal and benefit from:}

- Convenient online submission

- Rigorous peer review

- Open access: articles freely available online

- High visibility within the field

- Retaining the copyright to your article

Submit your next manuscript at $\boldsymbol{\nabla}$ springeropen.com 